\title{
ASPIRATION CURETTAGE IN A MILITARY HOSPITAL
}

\author{
COLONEL W. A. KIRKPATRICK, M.B., F.R.C.O.G., Late R.A.M.C. \\ Duchess of Kent's Military Hospital, Catterick
}

SUMMARY: The results of a trial of the Vabra aspirator and Reciprotor pump in the British Military Hospital (B.M.H.), Münster, are presented.

Patient acceptability was good and satisfactory histological specimens were obtained. These advantages were considered to outweigh the complication rate. Substantial personal and financial advantages to the Service are possible.

\section{Introduction}

In the Services, admission of a wife to hospital frequently means that her husband must be released from his normal duties to look after their children with consequent loss of military efficiency. As minor gynaecological operations account for many of these admissions, an outpatient alternative to dilatation and curettage (D\&C) has obvious attractions. The Vabra aspirator offers such an alternative and this paper presents the results of its use at the B.M.H. Münster between December 1971 and December 1973.

The apparatus, illustrated in Figure 1, has been described by Bjerre, Gardmårk and Sjöberg (1971), Holt (1970) and Jensen (1970). It was used with the 'Reciprotor' pump which can produce a negative pressure of $600 \mathrm{~mm}$ mercury in three seconds (Fig. 2).

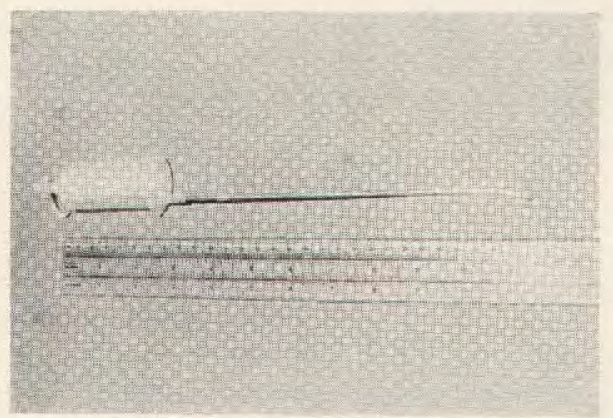

Fig. 1. The Vabra aspirator

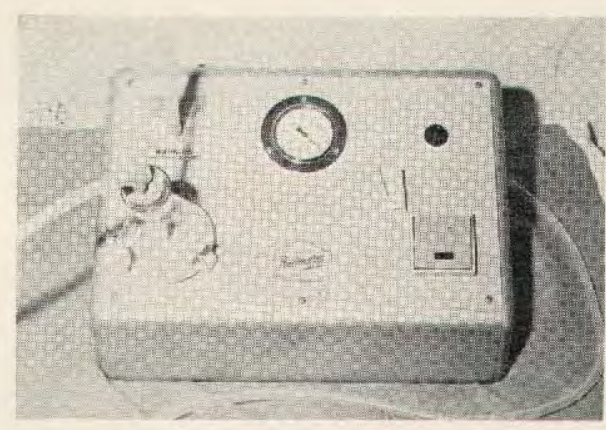

Fig. 2. 'Reciprotor' pump

\section{Material}

Aspiration curettage was performed 64 times on 63 patients using the technique described by Holt (1970) except that Cusco's bivalve speculum was used. As in his paper the criterion for inclusion was the need for curettage.

A questionnaire was prepared in which the patient was asked:

a. whether she experienced any discomfort during the procedure;

b. if 'yes' whether it was slight, moderate or severe;

c. whether she had ever previously had a 'D\&C' under a general anaesthetic. 
Only 57, questionnaires were eventually returned and the results are based on them. The procedures were carried out by a consultant, a senior specialist and a specialist.

After the first 39 cases, local anaesthesia was added by infiltrating the cervix with 1 per cent lignocaine as advised by Holt (1971).

\section{Results}

Table I shows the age distribution of the cases.

Table I

Age distribution in years

\begin{tabular}{|l|c|c|c|c|c|c|c|}
\hline Age & $20 \&$ less & $21-25$ & $26-30$ & $31-35$ & $36-40$ & $41-45$ & Over 45 \\
\hline Number & $4(7.2 \%)$ & $15(26.3 \%)$ & $13(22.8 \%)$ & $15(26.3 \%)$ & $6(10.5 \%)$ & $1(1.8 \%)$ & $3(5.3 \%)$ \\
\hline
\end{tabular}

As is to be expected of a service population, the majority are young, 82.5 per cent being under the age of 36 . This compares with 24 per cent in Jensen's (1970) series. Bjerre, Gardmårk and Sjöberg (1971), Haller et al (1973) and Nüssler, Thomsen and Weeth (1975) divide the groups differently, but all show a preponderance of older women.

The parity of the patients in this series varied between nil and 6,30 per cent being nulliparous. The presenting symptoms were sterility, post-coital bleeding and various menstrual disturbances.

On all but one occasion a specimen suitable for histological examination was obtained. The patient from whom insufficient material was obtained was bleeding at the time and had had a dilatation and curettage one month previously. The reports included proliferative phase, secretory phase, pre-menstrual phase and menstruating endometrium, endometrial hyperplasia, chronic endometritis and endocervicitis.

Table II shows the distribution of the degree of discomfort felt by the patients in the whole series. About half (28) had slight or no discomfort and the other half (29) had moderate or severe discomfort. These results may be compared with those of Holt (1970) who reported that 13 out of 60 patients complained of severe discomfort. Bjerre, Gardmårk and Sjöberg (1971), however, found that only 6.3 per cent considered the procedure 'painful'.

Table II

Degree of discomfort

\begin{tabular}{|l|c|c|c|c|c|}
\hline Degree & None & Slight & Moderate & Severe & Total \\
\hline Number & $9(15.8 \%)$ & $19(33.3 \%)$ & $18(31.6 \%)$ & $11(19.3 \%)$ & 57 \\
\hline
\end{tabular}

Tables III and IV indicate that local anaesthesia makes a considerable difference to the degree of discomfort felt, although the numbers in each table are small. Nüssler, Thomsen and Weeth (1975) had some better results using paracervical 
Table III

Degree of discomfort without local anaesthesia

\begin{tabular}{|l|c|c|c|c|c|}
\hline Degree & None & Slight & Moderate & Severe & Total \\
\hline Number & $4(10.0 \%)$ & $10(25.0 \%)$ & $15(37.5 \%)$ & $10(25.0 \%)$ & 39 \\
\hline
\end{tabular}

Table IV

Degree of discomfort with local anaesthesia

\begin{tabular}{|l|c|c|c|c|c|}
\hline Degree & None & Slight & Moderate & Severe & Total \\
\hline Number & $5(27.8 \%)$ & $9(50.0 \%)$ & $3(16.7 \%)$ & $1(5.6 \%)$ & 18 \\
\hline
\end{tabular}

block. However, tables $\mathrm{V}$ to $\mathrm{X}$ indicate the importance of a more personal factor, in that the consultant and senior specialist working without anaesthesia obtained better results than the specialist working with it.

Table $\mathbf{V}$

Degree of discomfort. Consultant operating without anaesthesia

\begin{tabular}{|l|c|c|c|c|c|}
\hline Degree & None & Slight & Moderate & Severe & Total \\
\cline { 2 - 4 } Number & $2(14.3 \%)$ & $5(35.7 \%)$ & $6(44.4 \%)$ & $1(7.15 \%)$ & 14 \\
\hline
\end{tabular}

Table VI

Degree of discomfort. Senior specialist operating without anaesthesia

\begin{tabular}{|l|c|c|c|c|c|}
\hline Degree & None & Slight & Moderate & Severe & Total \\
\hline Number & $1(20.0 \%)$ & $1(20.0 \%)$ & $2(40.0 \%)$ & $1(20.0 \%)$ & 5 \\
\hline
\end{tabular}

\section{Table VII}

Degree of discomfort. Specialist operating without anaesthesia

\begin{tabular}{|l|c|c|c|c|c|}
\hline Degree & None & Slight & Moderate & Severe & Total \\
\cline { 1 - 3 } & $1(5.0 \%)$ & $3(15.0 \%)$ & $8(40.0 \%)$ & $8(40.0 \%)$ & 20 \\
\hline
\end{tabular}

Table VIII

Degree of discomfort. Consultant operating with anaesthesia

\begin{tabular}{|l|c|c|c|c|c|}
\hline Degree & None & Slight & Moderate & Severe & Total \\
\hline Number & $4(44.4 \%)$ & $5(55.5 \%)$ & - & - & 9 \\
\hline
\end{tabular}

Table IX

Degree of discomfort. Senior specialist operating with anaesthesia

\begin{tabular}{|l|c|c|c|c|c|}
\hline Degree & None & Slight & Moderate & Severe & Total \\
\hline Number & $1(33.3 \%)$ & $2(66.6 \%)$ & - & - & 3 \\
\hline
\end{tabular}


Table X

Degree of discomfort. Specialist operating with anaesthesia

\begin{tabular}{|l|c|c|c|c|c|}
\hline Degree & None & Slight & Moderate & Severe & Total \\
\hline Number & - & $1(20.0 \%)$ & $3(60.0 \%)$ & $1(20.0 \%)$ & 5 \\
\hline
\end{tabular}

In an attempt to compare aspiration curettage with conventional dilatation and curettage from the patient's point of view, the patients were asked whether or not they had ever had a 'D\&C'. Thirty-six replied in the affirmative. Of these, 9 had had local anaesthesia for the aspiration curettage and 27 had not. Of the 9, 6 stated a preference for the aspiration curettage and of the 27, 21 were of the same mind. Those who had never had a 'D\&C' could not be expected to make a valid comparison.

\section{Complications}

Complications were recorded in 4 patients and are reported below.

Mrs. M. G. aged 25 years, multipara, had complained of epimenorrhagia for 3 months. No pelvic abnormality was found and aspiration curettage was carried out. Subsequently she bled intermittently about every other day for 3 months and so she was admitted for diagnostic curettage under general anaesthesia. No abnormality was found and she remained well thereafter. The histological report on both the specimens showed proliferative endometrium.

Mrs. J. S. aged 25 years, para 1, had a persistent red discharge following her first confinement. The only abnormal finding at aspiration curettage was a bulky uterus. Very little material was obtained and it consisted of endometrium in the secretory phase. Minimal bleeding continued for 6 days and was then followed by heavy bleeding for which she was admitted to hospital. Dilatation and curettage under general anaesthesia showed her to have 'acute or chronic endometritis'. She did not attend for review.

Mrs. E. G. aged 37 years, para 4, had an aspiration curettage because of epimenorrhagia. She was on oral anticoagulant therapy because of repeated episodes of deep venous thrombosis. The endometrium was in the proliferative phase. She bled vaginally for 3 days and then had severe bleeding which necessitated admission to a German Krankenhaus where she was treated with Vitamin $\mathrm{K}$ and had a conventional curettage. She was well thereafter.

Mrs. P. K. aged 23 years, para 2, had an aspiration curettage for epimenorrhea. Normal secretory phase endometrium was found. On return home, she bled heavily and was kept in bed for 3 days by her medical officer. She did not attend for review.

\section{Discussion}

It is clear from these results that the procedure is acceptable to patients. Of those qualified to make a comparison approximately two-thirds preferred outpatient aspiration curettage to conventional inpatient curettage, the proportion being apparently uninfluenced by whether or not local anaesthesia was used. The attitude 
and skill of the operator has considerable influence on the degree of discomfort reported by the patients, perhaps as much as the local anaesthetic. The specimens obtained are suitable for histological examination, as reported by Jensen (1970), Saunders and Roland (1972), McGarry and Pearce (1972), Nye and Craig (1973) and Nïssler, Thomsen and Weeth (1975).

The number of complications is high at 7 per cent. If the case on anticoagulant therapy is excluded the rate is 5.2 per cent which is similar to that reported by Nüssler, Thomsen and Weeth (1975). One case was evidently due to infection but no explanation was found for the bleeding in the two remaining cases.

In favour of aspiration curettage are:

a. there is no waiting list; patients are dealt with on the day of consultation;

b. there is no interference with the military duties of the patients' husbands;

c. the cost of inpatient care is saved. With the advent of cryosurgery, these benefits will even be more apparent.

Against the procedure are the rate of complications and irreducible degree of discomfort experienced.

The advantages are considered to outweigh the disadvantages.

\section{REFERENCES}

BJerre, B. A., Gardmark, S. A. and Sjoberg, N-Oja (1971). J. Reprod. Med. 7, 221.

Haller, U., Kubli, F., Braunig, G., Muller, H. and Castanno y Almendral, A. (1973). Gerburtsh. u. Frauenheilk. 33, 1-13.

HoLt, E. M. (1970). J. Obstet. Gynaec. Brit. Cwlth. 77, 1043.

HoLT, E. M. (1971). (personal communication)

JeNSEN, J. G. (1970). Dan. med. Bull. 7, 199.

McGarry, J. M. and Pearce, M. A. (1972). Brit. J. clin. Pract. 10, 473.

Nussler, E., Thomsen, P. B. and Weeth, R. (1975). Dan. med. Bull. 4, 165.

NyE, E. B. and CrAig, G. A. (1973). Amer, J. Obstet, Gynec. 2, 181.

Saunders, P. and Rowland, R. (1972). J. Obstet. Gynec. Brit. Cwlth. 79, 168.

\section{Appointments to The Queen}

Queen's Honorary Physician

Colonel T. C. Dow, T.D., M.B., Ch.B., R.A.M.C. (T.A.V.R.), is appointed Honorary Physician to The Queen as from 21 March 1977, in succession to Colonel F. L. Constable, T.D., M.D., F.R.C.Path. on completion of his tenure.

\section{Queen's Honorary Surgeon}

Colonel T. H. L. Bryson, T.D., M.B., Ch.B., F.F.A.R.C.S., R.A.M.C. (T.A.V.R.), is appointed Honorary Surgeon to The Queen as from 21 March 1977, in succession to Colonel D. N. Stewart, T.D., M.R.C.S., L.R.C.P., D.L.O. on completion of his tenure. 